\title{
Possible mechanism of host manipulation resulting from a diel behaviour pattern of eye-dwelling parasites?
}

\author{
ANTHONY D. STUMBO* and ROBERT POULIN \\ Department of Zoology, University of Otago, 340 Great King Street, PO Box 56, Dunedin 9054, New Zealand
}

(Received 7 December 2015; revised 21 March 2016; accepted 6 April 2016; first published online 24 May 2016)

\begin{abstract}
SUMMARY
Parasitic infection often results in alterations to the host's phenotype, and may modify selection pressures for host populations. Elucidating the mechanisms underlying these changes is essential to understand the evolution of host-parasite interactions. A variety of mechanisms may result in changes in the host's behavioural phenotype, ranging from simple by-products of infection to chemicals directly released by the parasite to alter behaviour. Another possibility may involve parasites freely moving to certain sites within tissues, at specific times of the day to induce behavioural changes in the host. We tested the hypothesis that parasites shift to certain sites within the host by quantifying the location and activity of the trematode Tylodelphys sp., whose mobile metacercarial stages remain unencysted in the eyes of the second intermediate fish host, the common bully (Gobiomorphus cotidianus). This parasite's definitive host is a piscivorous bird feeding exclusively during daytime. Ocular obstruction and metacercarial activity were assessed within the sedated host's eye at three time points $24 \mathrm{~h}^{-1}$ period, using video captured via an ophthalmoscope. Although observed metacercarial activity did not change between time periods, ocular obstruction was significantly reduced at night. Increased visual obstruction specifically during the foraging time of the parasite's definitive host strongly suggests that the parasite's activity pattern is adaptive.
\end{abstract}

Key words: parasite-host interactions, parasite phenotype, parasite behaviour, host manipulation, trematode.

\section{INTRODUCTION}

While there are many well-documented examples of altered behaviour in parasitized hosts, ranging from simple twitching to complex changes in host personality (see Moore, 2002; Thomas et al. 2005; Poulin, 2010), it remains difficult to categorize a change in host behaviour as either a fortuitous by-product of infection or a genuine adaptive manipulation, and to determine how it alters the selection pressure on the host. This is due, in part, to the difficulty in identifying the mechanism causing the altered behaviour (see Adamo and Webster, 2013). Understanding these mechanisms will further our understanding of the selection pressures on parasites resulting in parasite-mediated changes in host behaviour, hostparasite interactions and coevolution, and how parasites shape the evolution of their host (Poulin, 2007; Schmid-Hempel, 2011).

Although the number of known mechanisms pales in comparison with the known examples of altered behaviour, a great deal of knowledge has been gained about the physiology and evolution of both parasite and host. Alterations to the neurochemistry of the host and infection of the host's central nervous system are the most well-understood mechanisms of parasite-mediated behaviour (Lafferty and Shaw, 2013). A well-known example is Toxoplasma

* Corresponding author: Department of Zoology, University of Otago, 340 Great King Street, PO Box 56, Dunedin 9054, New Zealand. E-mail: stumboan@gmail.com gondii, a protozoan that infects felids as its definitive (primary) (Hill et al. 2005). Compared with uninfected conspecifics, rats (Rattus spp.) acting as second intermediate hosts show diminished cognitive ability, increased activity and exploratory behaviour, and reduced neophobia, increasing the likelihood of transmission (see Webster, 2007 for review). Toxoplasma gondii-infected rats also exhibit reduced fear of, and sometimes attraction to, felid odour, while remaining cautious of nonfelid predators (Berdoy et al. 2000; Webster, 2007; Lamberton et al. 2008). Though not fully understood, these altered behaviours appear to be mediated by several factors including a higher rate of infection in, and inflammation of, the amygdala and hypothalamus (Hermes et al. 2008; Berenreiterová et al. 2011; Haroon et al. 2012) and increased dopamine synthesis via tyrosine hydroxylase produced by $T$. gondii (Rohrscheib and Brownlie, 2013). These mechanisms by which the parasite alters and manipulates host neurological systems to achieve the resulting behaviour teaches us about the physiology of the altered systems (Adamo, 2013).

A variety of less complex mechanisms, such as targeting and damaging certain tissues of the host, have also been shown to alter host behaviour (Lafferty and Shaw, 2013). For instance, metacercarial stages of the trematode Diplostomum spathaceum invade the eyes of its fish intermediate host, awaiting ingestion by its bird definitive host. The intensity of 
D. spathaceum infection in rainbow trout (Onocorhynchus mykiss) directly correlates with cataract intensity in the fish's eyes (Karvonen et al. 2004). The formation of these cataracts has been shown to reduce vision and increase the trout's susceptibility to simulated avian predation (Seppälä et al. 2004), while not impeding its ability to escape fish predators (Seppälä et al. 2006). Although the cataracts are a result of metabolic wastes produced by the parasite, as well as mechanical destruction and protein alteration resulting from infection (Ersdal et al. 2001; Seppänen et al. 2008), selection pressure should maintain or enhance the exaptation behaviour if it furthers the transmission of the parasite (Poulin, 2010).

An often overlooked factor in host manipulation is the phenotype of the parasites themselves. For example, in trophically transmitted helminths, selection would favour simple behaviours in parasites if these improve transmission by altering the host's phenotype. This can be seen with Leucochloridium paradoxum trematodes, which form conspicuouslycoloured broodsacs, migrate to the tentacles of terrestrial snails and pulsate rapidly; the snails' eye stalks consequently resemble caterpillars, presumably resulting in increased predation by the definitive bird host (Wesołowska and Wesołowski, 2014). Few, if any, examples exist that demonstrate the behavioural phenotype of the parasite acting as a mechanism for altered behaviour in the host, i.e. the parasite's actions actually causing changes in host behaviour. This is not for a lack of documented parasite behaviours. The behaviours of several trematode developmental stages (e.g. cercariae, miracidia) have been well characterized; however, these have not been examined in the context of host manipulation (see Lewis et al. 2002). In trematodes with a typical three-host life cycle, known behaviour of metacercariae that infect the second intermediate host, which is often the host that shows altered behaviour, is limited to site selection (Lafferty, 2002; e.g. Matisz et al. 2010). In most species, metacercariae encapsulate in a cyst and are considered passive; however they are not fully dormant and remain active, and some metacercariae (e.g. diplostomulum type) even remain unencysted, staying active and mobile.

The trematode Tylodelphys sp. forms diplostomulum-type metacercariae that remain unencysted and infect the vitreous humour of the eyes of New Zealand common bully (Gobiomorphus cotidianus, McDowall, 1975), their second intermediate host (Fig. 1). These metacercariae are mobile and active between the fish's lens and retina, and can cross from one side of the eye to the other in a matter of seconds. They provide an excellent opportunity to study parasite behaviour. Tylodelphys sp. metacercariae could maximize the probability of successful transmission and minimize unnecessary damage to

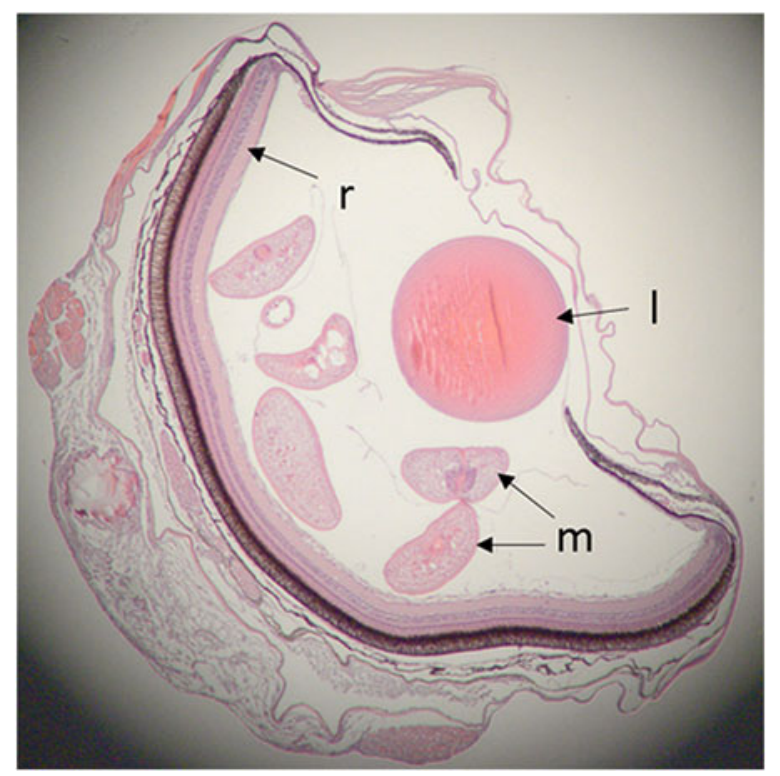

Fig. 1. Histological section $(5-\mu \mathrm{m})$ of a common bully Gobiomorphus cotidianus eye infected with Tylodelphis sp. metacercariae $(\mathrm{m})$, with lens $(\mathrm{l})$ and retina $(\mathrm{r})$ indicated.

the host by following a circadian behavioural rhythm, obscuring vision during the day when the parasite's definitive avian host (the great crested grebe, Podiceps cristatus) is foraging while leaving the eye fully functional at dusk and beyond. If such selection pressures acted on the natural oscillations of the parasite, its activity and distribution should be greater during the day, and reduced at night.

We tested this hypothesis by observing Tylodelphys sp. metacercariae using an ophthalmoscope with video output, thus capturing the movement of the metacercariae within the eyes of live hosts at three different time periods (sunrise, midday and night), and assessing the level of retinal obstruction caused by the metacercariae, as well as the parasites' actual movements. The extent to which vision is impeded should also (i) increase with intensity of infection assuming that the metacercariae do not achieve smaller sizes when intensity is high, and (ii) be greater if both eyes are affected equally. Thus, necropsy data were used to determine whether the number of metacercariae is roughly equal between the left and right eyes of fish. Metacercarial sizes were also measured via photo analysis to gauge the level of intrahost density-dependent growth. Finally, pathological assessment of infected eyes was also performed using histology to determine if Tylodelphys sp. infection causes any damage to the inner eye, which would impede vision regardless of time of day.

\section{MATERIALS AND METHODS}

Infected bullies were collected from Lake Hayes $\left(44^{\circ}\right.$ $\left.58^{\prime} 08 \cdot 0^{\prime \prime} \mathrm{S} 168^{\circ} 48^{\prime} 44 \cdot 6^{\prime \prime} \mathrm{E}\right)$ in Central Otago, New 
Zealand, in January of 2014, and transported to the University of Otago. Fish were housed for 4 weeks, with a 12/12 L/D light cycle and fed commercial pellets (Ridley AquaFeeds Pty Ltd, Narangba, Qld. Australia) ad libitum. Adult bullies (47.4 $\pm 7 \cdot 4$ $\mathrm{mm}$ s.E.) were used to standardize the necessary dose of anaesthetic, and to insure uniform eye sizes.

\section{Video acquisition}

Bullies $(n=12)$ were anesthetized with MS-222 (Tricaine mesylate, $100 \mathrm{mg} \mathrm{L}^{-1}$ ), and a binocular indirect ophthalmoscope (Neitz IO- $\alpha$ TV) with video output was used to capture $30 \mathrm{~s}$ videos of the fish's interior eye at five different angles. Using a line perpendicular to the pupil as the base angle, adjusting for a consistent eye slant of $100^{\circ}$ from horizontal, four additional angles with an adjustment of $12^{\circ}$ from the centre were filmed in opposite directions (i.e. up, down, front and back). An angle adjustment of $12^{\circ}$ was chosen based on of preliminary trials as well as to limit angle overlap at the retina surface $\left(\tan ^{-1}(1 / 2\right.$ pupil width/eye depth); pupil width $=1 \cdot 75-\mathrm{mm}$, eye depth $=4-\mathrm{mm}$, see Supplementary Fig. 1A). The ophthalmoscope was attached to a pivoting mount $110-\mathrm{mm}$ from the fish, allowing for quick and consistent changes in camera angle, and fish were placed on an attached platform that could be adjusted vertically for consistent pupil placement. A $10 \times$ magnifying glass was also attached to the mount 36- $\mathrm{mm}$ from the ophthalmoscope for the increased magnification necessary to observe the fish's inner eye.

Videos were taken for each individual fish at three different time periods. These times corresponded to the beginning of the photophase ('sunrise'), $8 \mathrm{~h}$ later ('midday'), and $8 \mathrm{~h}$ after that (i.e. $4 \mathrm{~h}$ into the scotophase, or 'night'). As a precautionary method to reduce alterations to the fish's photoperiod, a red filter was used on the ophthalmoscope's light during all time periods, and a desk lamp with a 60watt red light bulb was used exclusively at night. Red light was selected because of its use in several aquatic behavioural observations (e.g. Jury et al. 2001; Mills et al. 2005), including two common bully studies (Bassett et al. 2006; Vanderpham et al. 2012), and because red light has been shown to be less aversive to fish than white light (e.g. Widder et al. 2005; Raymond and Widder, 2007). A third of the fish had their first recording trial at each of the three time periods to control for possible bias. After trials were completed, fish were euthanized with MS-222 (1-g L $\left.{ }^{-1}\right)$ for necropsy, and metacercariae intensity was assessed for each eye. A paired sample $t$-test was used to test for a possible difference in infection intensity between the left and the right eye. Metacercariae from the observed eye were then placed between a slide and coverslip and photographed at $4 \cdot 5 \times$ magnification under a dissecting microscope (Olympus SZ61) with equipped camera (Olympus DP25). ImageJ (1.48v, U.S. National Institutes of Health, Bethesda, Maryland, USA) was used to determine the size (body surface, $\mu \mathrm{m}^{2}$ ) of each metacercaria, and an average metacercarial size was calculated for each eye. A simple regression analysis was used to assess the relationship between metacercariae intensity and average metacercarial size.

\section{Video analysis}

Each of the resulting videos (five per angle per time period) was reduced to ten still images, one every $3 \mathrm{~s}$. Image J was used to create a binary mosaic of pixels, each indicating presence or absence of metacercariae. These binary pictures were transformed into Microsoft Office Excel (v. 2013) data files, where each cell in a grid represented a pixel, with ' 1 ' indicating parasite presence for an individual pixel (i.e. the parasite's body covered that pixel) and ' 0 ' indicating parasite absence. The resulting files were used to assess metacercariae activity and retinal obstruction caused by metacercariae.

Metacercariae Activity: Metacercariae activity was assessed by assigning a value of ' 1 ' to a pixel if there was a change in parasite presence/absence between consecutive images in the sequence, and a value of ' 0 ' if the parasite presence/absence was the same (e.g. $0 \rightarrow 0=0,0 \rightarrow 1=1)$. A value of 1 indicated that the metacercaria either entered or exited that pixel space between images, representing movement of the metacercaria. The values were then summed at each pixel location, giving a total amount of movement at that location for that video. An end value of ' 0 ' was indicative of no observable movement (i.e. pixel location remained occupied or empty throughout the video), and was a representation of space coverage rather than activity. These ' 0 ' values were removed to obtain active movement space, and the remaining values were summed and divided by the number of remaining pixels to get an assessment of overall metacercarial movement for each video set. A repeated measures linear mixed-effects model was run in $\mathrm{R} 3.2 .3$ ( $\mathrm{R}$ Core Team, 2015) with the lme function (nlme package, Pinheiro et al. 2015). Metacercariae activity was treated as the dependent variable, time as the within-subject variable, and metacercariae intensity as the between-subjects variable.

Retinal Obstruction: Retinal obstruction for each video was assessed by averaging the value ( 0 or 1$)$ of each pixel location at each time period over all 10 frames analysed. Only the portion of the images corresponding to each unique video angle (Supplementary Fig. 1B) was used for each sequence to avoid overlap with the other videos obtained for each individual fish (see Supplementary Fig. 1A). All videos for an individual fish during the time 
period were then averaged to get an overall retinal obstruction per fish per time period. A repeated measures linear mixed-effects model was run with the lme function in $\mathrm{R}$ 3.2.3, with retinal obstruction treated as the dependent variable, time as the withinsubject variable, and metacercariae intensity as the between-subjects variable.

\section{Histopathology}

Histological sectioning was used for a qualitative assessment of tissue damage within the eyes of infected bullies. Infected $(n=3)$ and uninfected bullies $(n=$ 2) were euthanized with MS-222 $\left(1-\mathrm{g} \mathrm{L}^{-1}\right)$ and their eyes were removed, fixed in Davidson's Fixative for $24 \mathrm{~h}$, and stored in $10 \%$ neutralbuffered formalin for 2 days. Tissue was dehydrated with ethanol containing $4 \%$ phenol, followed by xylene, and embedded in paraffin. Each eye was serially sectioned along the horizontal plane (5 $\mu \mathrm{m}$ thickness) and mounted on slides. Sections were stained with haematoxylin and eosin and examined by light microscopy. The qualitative analysis was performed by comparing infected and uninfected tissue, and looking for damage characteristic of that was found in Grobbelaar et al. (2015) and described in Bullard and Overstreet (2008) and Purivirojkul (2012). The number of metacercariae per eye was estimated via the histological slides.

\section{Ethical note}

All procedures described here follow the New Zealand legislation on animal use in research, and have been specifically approved by the University of Otago's Animal Ethics Committee (permit 83-13).

\section{RESULTS}

The mean number of metacercariae per eye was $7 \cdot 7$ (range 1-17). We found no difference in infection levels between the left and right eyes of the bully hosts $\left(t_{11}=0.55, P=0.587\right)$, indicating a somewhat equal level of infection between the two eyes. A negative relationship was seen between the number of metacercariae in an eye and average metacercarial size $\left(F_{1,11}=7 \cdot 47, P=0 \cdot 021, R^{2}=0 \cdot 4276\right)$. A comparison of infected to uninfected eyes did not reveal any apparent damage to retinal tissue caused by metacercariae presences, such as increased spacing of photo receptors (a by-product of retinal stretching), cytologic damage, hyperplasia, hypertrophy, or layer thinning.

The repeated measures linear mixed-effects model revealed that retinal obstruction (i.e. the percentage of the observable retina obscured by metacercariae) was significantly less at 'Night' compared with the 'Midday' $\left(t_{22}=7 \cdot 898, \quad P<0 \cdot 001\right)$ and 'Morning' $\left(t_{22}=8.695, P<0.001\right)$ treatments, which did not significantly differ from each other $\left(t_{22}=0.797, P\right.$ $=0.434)$ (Fig. 2). However, the analysis failed to show any significant relationship between metacercariae intensity and retinal obstruction $\left(t_{10}=0.032\right.$, $P=0.975$ ). Metacercariae activity (Fig. 3) did not differ between 'Morning' and 'Midday' $\left(t_{22}=0.996\right.$, $P=0.330)$, 'Morning' and 'Night' $\left(t_{22}=0.778\right.$, $P=0.445)$, or 'Midday' and 'Night' $\left(t_{22}=0.217\right.$, $P=0.830)$, and was not dependent on metacercariae intensity $\left(t_{10}=1 \cdot 801, P=0 \cdot 128\right)$. Overall, metacercariae were shown to primarily occupy the lower portion of the vitreous humour, extending into the open region of the humour during the day, resulting in increased overlap with the retina (Fig. 4).

\section{DISCUSSION}

Our analysis is one of the first to look at parasite behaviour as a possible mechanism for altered host behaviour, demonstrating that the behavioural phenotype of a parasite larva may have implications for the phenotype of the host. The number of metacercariae did not significantly affect the results of our activity or obstruction analysis, indicating that it is where the parasites locate themselves at certain times of the day that matters, and not merely the number of parasites present. The level of ocular obstruction varied highly significantly among time periods. Throughout the video analysis, it was apparent that metacercariae spent the greatest amount of time in the lower portion of the vitreous chamber (Fig. 4). From the bottom of the chamber, metacercariae extended upwards during daytime hours in a parallel orientation to the lens of the eye, resulting in a maximum amount of lens obstruction and a sagittal overlap of the metacercariae. Although the metacercariae are fairly large (mean body length \pm s.e., $1773 \cdot 5 \pm 71 \cdot 20 \mu \mathrm{m}$; body width, $525 \cdot 9 \pm 19 \cdot 4 \mu \mathrm{m}$ ), the depth of the humour appears to provide sufficient room for relatively large numbers of metacercariae, causing them to overlap without additive effects on retinal obstruction. In addition, the negative correlation between metacercariae size and intensity indicates densitydependent growth limitation, i.e. diminishing returns in terms of retinal obstruction with each new metacercaria. Thus, the lack of an effect of parasite intensity is likely due to the overlap of the metacercariae in the vitreous humour, as well as the decreasing size of metacercariae at higher intensities. The overlapping of the metacercariae may have some interesting effects, however, due to their semi-transparent bodies, as multiple moving flukes may result in a shifting of light intensity over the retina.

Results from our ocular obstruction analysis indicate that the Tylodelphis sp. metacercariae exhibit a temporal change of positioning within the host's eye, primarily occupying the lower region of the 


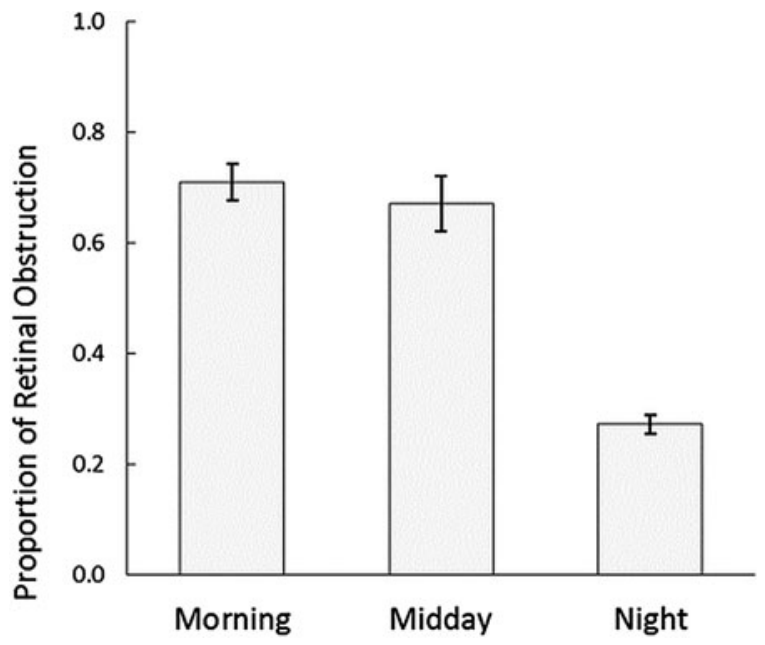

Fig. 2. Proportion (mean \pm s.E.) of the fish's retina obstructed by Tylodelphis sp. metacercariae at three different time points ( $8 \mathrm{~h}$ intervals). Twelve fish were tested at all three time periods.

vitreous humour at night and expanding into the central region during the day. This diel behaviour, as well as the size and orientation of the metacercariae, ultimately results in increased retinal obstruction during the day, with equal infection intensities between the left and right eyes causing more-orless uniform visual obstruction. Other means of visual obstruction, such as cataract formation and increased water turbidity, have been shown to impact fish foraging, mate selection and predator avoidance (e.g. Seppälä et al. 2004; Meager and Batty, 2007; Maan et al. 2008). The reduction in the diurnal vision of Tylodelphis sp. infected bullies provides a strong indication that these same changes in behaviour and ecological interactions may exist for infected bullies. Further, the diel nature of the visual obstruction observed in our study adds a level of complexity beyond fixed mechanisms, such as cataract formation, which may ultimately alter the diel behaviour of the host.

Cataract formation resulting from Diplostomum metacercariae infection has been shown to increase the susceptibility of fish to avian predation (e.g. Seppälä et al. 2004), with higher metacercarial abundance, resulting in larger and more visually intrusive cataracts (Seppälä et al. 2011). The crested grebe (Podiceps cristatus), the most likely definitive host of Tylodelphis sp., is a surface-diving piscivorous bird that has been documented foraging from dawn to dusk, with no nocturnal feeding (e.g. O’Donnell, 1982; Ulenaers and van Vessem, 1994; Gwiazda, 1997). By obscuring vision during the day, Tylodelphis sp. metacercariae may limit the bully's ability to perceive visual cues of this predatory threat in a similar manner to Diplostomuminduced cataracts, favouring completion of the trematode's life cycle. The primary aquatic predator of known infected bully populations, not counting

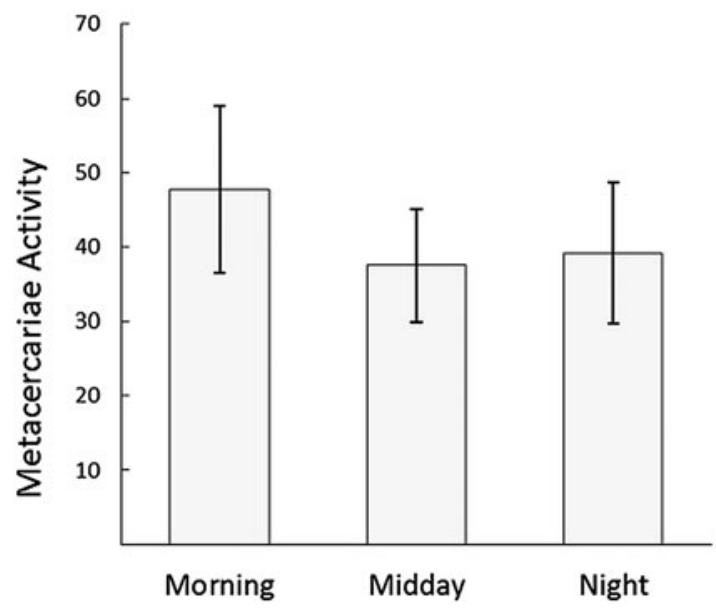

Fig. 3. Movement of Tylodelphis sp. metacercariae over time in the eye of fish hosts $(n=12)$, at three different time points ( $8 \mathrm{~h}$ intervals), represented by mean ( \pm s.E.) change in pixel occupation during video observation. Twelve fish were tested at all three time periods.

invasive and conspecific threats, is the nocturnal longfin eel (Anguilla dieffenbachii). This predator cannot act as a suitable host for Tylodelphis sp., and consumption of infected bullies by this predator is an effective dead-end for the parasite. If visual obstruction were to persist during the nocturnal hours, this obstruction may severely or fully blind the bully to non-host predation during periods of limited illumination. Overall, the diurnality of the definitive host and nocturnality of the dead-end predator suggest that the observed metacercariae behaviour may be the result of selection pressure on the diel oscillations of Tylodelphis sp. metacercariae.

The tendency of the metacercariae to primarily position themselves in the lower region of the vitreous humour also indicates a further consequence regarding crested grebe predation. The refraction of light from air to water limits light penetration from the surface to $48 \cdot 6^{\circ}$ from vertical (Snell's law; Lythogoe, 1979). The surface outside of this $97 \cdot 2^{\circ}$ circle (Snell's window) is illuminated solely by light reflected from below, hindering a fish's ability to detect avian predation (Katzir and Camhi, 1993). The increased obstruction of the retina in the lower region of the vitreous humour would partially limit the bully's ability to perceive threats from within Snell's Window, with diurnal expansion of the metacercariae into the vitreous humour causing further obstruction.

The time-specific movement of the metacercariae into the open region of the vitreous humour may also be a by-product of the feeding behaviour of the larval trematodes. Non-encysting metacercariae possess an elaborate morphology compared with their encysting counterparts, showing advanced organ development and a functioning gut, allowing for active feeding until host death or ingestion (Erasmus, 1972; Galaktionov and Dobrovolskij, 


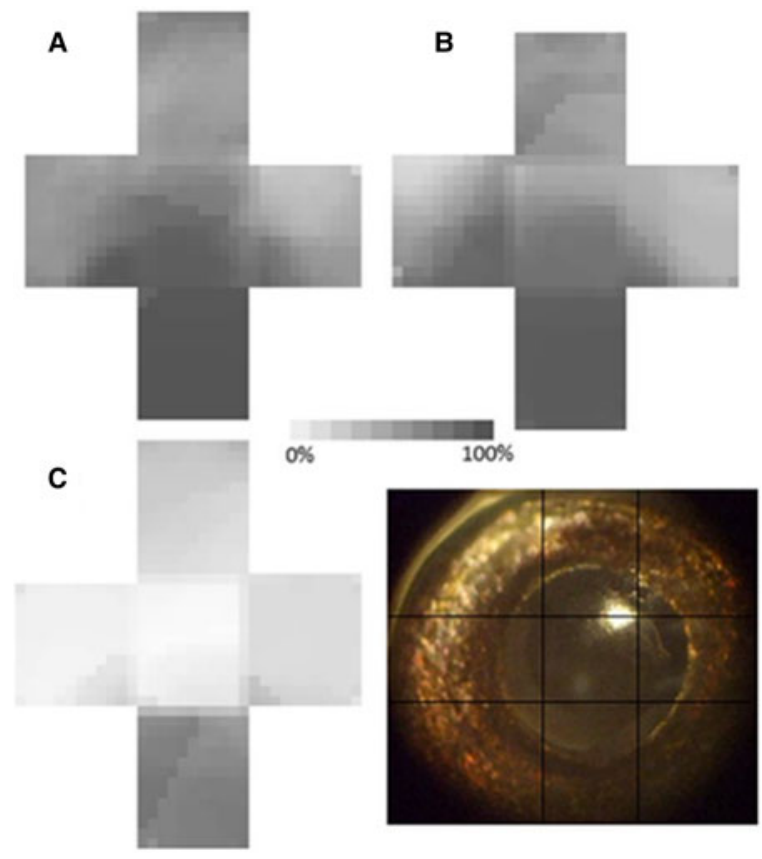

Fig. 4. A visual representation of retinal obstruction over time, at three different time intervals: morning (A), midday (B) and night (C). A darker pixel colour represents a greater proportion of time that space was occupied by metacercariae. Fish eye image by Isa Blasco-Costa.

2003). Rather than relying on endogenous food reserves, active feeding by metacercariae on host tissue provides energy at the expense of the host for movement/migration, growth and development, and accelerated morphogenetic processes (Bullard and Overstreet, 2008; Petrov and Podvyaznaya, 2015, e.g. for pre-encysting metacercariae: Matisz and Goater, 2010; Stumbo et al. 2012). Tylodelphis sp. does not appear to be an exception, possessing the complex morphology seen in other strigeoid metacercariae such as paired digestive caeca (Galaktionov and Dobrovolskij, 2003). This suggests that Tylodelphis sp. actively feeds on the fluid of the vitreous humour, providing energy for its initial development and activity and, subsequently, imposing an energetic demand on the host. The metacercariae may exhibit increased feeding during the day by capitalizing on the open region of the vitreous humour, strategically or inadvertently when vision obstruction would be beneficial to trophic transmission, and reduce the metabolic demand on the host at night (when vision obstruction is unnecessary). If this hypothesis is incorrect, and nutrient consumption is not augmented by the expansion of the metacercariae into the central region of the inner eye, then this behaviour may be indicative of a metabolic cost beyond necessary nutrient consumption for development. With increased metabolic drain on the host already exerted by the active feeding characteristic of non-encysting metacercariae, settling to the lower region of the eye would limit the energy consumption required for expansion into the central region of the vitreous humour.

This study is unique in demonstrating diel behaviour in metacercariae, although diel behaviour has been observed in other larval stages of trematode species. One obvious example is the synchronized release of cercariae, providing maximum overlap with the foraging activity of the target host (Theron, 1984; Combes et al. 1994). Overall though, the behaviour of endo-parasites is often neglected outside of their free-swimming larval stages such as miracidia and cercariae, and these examples are often limited to host detection/seeking (e.g. Combes et al. 1994; Haas et al. 1995). Further, metacercariae are often considered passive and lacking behaviour beyond initial site selection (Lafferty, 2002). Our study has demonstrated that metacercariae, at least non-encysting forms, can exhibit a complex behavioural phenotype, and hints that the behavioural phenotype of parasite larval stages may play a substantial role in furthering their life history.

\section{SUPPLEMENTARY MATERIAL}

The supplementary material for this article can be found at http://dx.doi.org/10.1017/S00311820160 00810 .

\section{ACKNOWLEDGEMENTS}

We thank Isa Blasco-Costa, Matthew Downes and Scott Jarvie for technical assistance, Gordon Sanderson and the Dunedin School of Medicine for loaning the ophthalmoscope, and the Otago Parasite Ecology Lab for comments on an earlier version.

\section{FINANCIAL SUPPORT}

This research was funded by the University of Otago through a scholarship to A. D. S. and a grant to R. P.

\section{REFERENCES}

Adamo, S. A. (2013). Parasites: evolution's neurobiologists. Fournal of Experimental Biology 216, 3-10.

Adamo, S. A. and Webster, J.P. (2013). Neural parasitology: how parasites manipulate host behaviour. Fournal of Experimental Biology 216, 1-2.

Bassett, D. K., Carton, A. G. and Montgomery, J. C. (2006). Flowing water decreases hydrodynamic signal detection in a fish with an epidermal lateral-line system. Marine and Freshwater Research 57, 611-617.

Berdoy, M., Webster, J. P. and Macdonald, D. W. (2000). Fatal attraction in rats infected with Toxoplasma gondii. Proceedings of the Royal Society B: Biological Sciences 267, 1591-1594.

Berenreiterová, M., Flegr, J., Kuběna, A. A. and Němec, P. (2011). The distribution of Toxoplasma gondii cysts in the brain of a mouse with latent toxoplasmosis: implications for the behavioral manipulation hypothesis. PLoS ONE 6, e28925.

Bullard, S. A. and Overstreet, R. M. (2008). Digeneans as enemies of fishes. In Fish Diseases (ed. Eiras, J. C., Segner, H., Wahli, T. and Kapoor, B. G.), Vol. 2, pp. 817-976. Science Publishers, Enfield, NH. Combes, C., Fournier, A., Moné, H. and Théron, A. (1994). Behaviours in trematode cercariae that enhance parasite transmission: patterns and processes. Parasitology 109, S3-S13.

Erasmus, D. A. (1972). The Biology of Trematodes. Edward Arnold Limited, London, UK. 
Ersdal, C., Midtlyng, P. J. and Jarp, J. (2001). An epidemiological study of cataracts in seawater farmed Atlantic salmon Salmo salar. Diseases of Aquatic Organisms 45, 229-236.

Galaktionov, K. V. and Dobrovolskij, A. A. (2003). The Biology and Evolution of Trematodes. Kluwer Academic Publishers, Dordrecht, The Netherlands.

Grobbelaar, A., van As, L. L., van As, J. G. and Butler, H. J. B. (2015). Pathology of eyes and brain of fish infected with diplostomids, southern Africa. African Zoology 50, 181-186.

Gwiazda, R. (1997). Foraging ecology of the Great Crested Grebe (Podiceps cristatus L.) at a mesotrophic-eutrophic reservoir. Hydrobiologia 353, 39-43.

Haas, W., Haberl, B., Kalbe, M. and Kömer, M. (1995). Snail-hostfinding by Miracidia and Cercariae: chemical host cues. Parasitology Today 11, 468-472.

Haroon, F., Händel, U., Angenstein, F., Goldschmidt, J., Kreutzmann, P., Lison, H., Fischer, K.-D., Scheich, H., Wetzel, W., Schlüter, D. and Budinger, E. (2012). Toxoplasma gondii actively inhibits neuronal function in chronically infected mice. PLoS ONE 7, e35516.

Hermes, G., Ajioka, J.W., Kelly, K. A., Mui, E., Roberts, F., Kasza, K., Mayr, T., Kirisits, M. J., Wollmann, R., Ferguson, D. J. P., Roberts, C. W., Hwang, J.-H., Trendler, T., Kennan, R. P., Suzuki, Y., Reardon, C., Hickey, W. F., Chen, L. and McLeod, R. (2008). Neurological and behavioral abnormalities, ventricular dilatation, altered cellular functions, inflammation, and neuronal injury in brains of mice due to common, persistent, parasitic infection. Fournal of Neuroinflammation $\mathbf{5}, 48$.

Hill, D. E., Chirukandoth, S. and Dubey, J. P. (2005). Biology and epidemiology of Toxoplasma gondii in man and animals. Animal Health Research Reviews 6, 41-61.

Jury, S. H., Howell, H., O'Grady, D. F. and Watson, W. H., III (2001). Lobster trap video: in situ video surveillance of the behaviour of Homarus americanua in and around traps. Marine and Freshwater Research $\mathbf{5 2}$, 1125-1132.

Karvonen, A., Seppälä, O. and Valtonen, E. T. (2004). Eye flukeinduced cataract formation in fish: quantitative analysis using an ophthalmological microscope. Parasitology 129, 473-478.

Katzir, G. and Camhi, J. M. (1993). Escape response of black mollies (Poecilia sphenops) to predatory dives of a pied kingfisher (Ceryle rudis). Copeia 1993, 549-553.

Lafferty, K. D. (2002). Inter-specific interactions in trematode communities. In The Behavioral Ecology of Parasites (ed. Lewis, E. E., Sukhdeo, M. V. K and Campbell, J. F.), pp. 153-169. CABI International, Wallingford, Oxon, UK.

Lafferty, K. D. and Shaw, J. C. (2013). Comparing mechanisms of host manipulation across host and parasite taxa. The Fournal of Experimental Biology 216, 56-66.

Lamberton, P.H. L., Donnelly, C.A. and Webster, J.P. (2008). Specificity of the Toxoplasma gondii-altered behaviour to definitive versus non-definitive host predation risk. Parasitology 135, 1143-1150.

Lewis, E. E., Campbell, J. F. and Sukhdeo, M. V. K. (2002). The Behavioural Ecology of Parasites. CABI, New York, NY.

Lythogoe, J. N. (1979). The Ecology of Vision. Clarendon Press; Oxford University Press, Oxford.

Maan, M. E., Van Rooijen, A.M.C., Van Alphen, J.J.M. and Seehausen, O. (2008). Parasite-mediated sexual selection and species divergence in Lake Victoria cichlid fish. Biological Fournal of the Linnean Society 94, 53-60.

Matisz, C. E. and Goater, C. P. (2010). Migration, site selection, and development of Ornithodiplostomum sp. metacercariae (Digenea: Strigeoidea) in fathead minnows (Pimephales promelas). International fournal for Parasitology 40, 1489-1496.

Matisz, C. E., Goater, C. P. and Bray, D. (2010). Migration and site selection of Ornithodiplostomum ptychocheilus (Trematoda: Digenea) metacercariae in the brain of fathead minnows (Pimephales promelas). Parasitology 137, 719-731.

Meager, J. J. and Batty, R. S. (2007). Effects of turbidity on the spontaneous and prey-searching activity of juvenile Atlantic cod (Gadus morhua). Philosophical Transactions of the Royal Society B 362, 2123-2130.
Mills, D. J., Verdouw, G. and Frusher, S. D. (2005). Remote multicamera system for in situ observations of behaviour and predator/prey interactions of marine benthic macrofauna. New Zealand Fournal of Marine and Freshwater Research 39, 347-352.

Moore, J. (2002). Parasites and the Behavior of Animals. Oxford University Press, Oxford

O'Donnell, C. F. J. (1982). Food and feeding behaviour of the Southern Crested Grebe on the Ashburton Lakes. Notornis 29, 151-156.

Petrov, A. and Podvyaznaya, I. (2015). Muscle architecture during the course of development of Diplostomum pseudospathaceum Niewiadomska, 1984 (Trematoda, Diplostomidae) from cercariae to metacercariae. Fournal of Helminthology 1-16.

Pinheiro, J., Bates, D., DebRoy, S., Sarkar, D. and R Core Team (2015). nlme: Linear and Nonlinear Mixed Effects Models.

Poulin, R. (2007). Are there general laws in parasite ecology? Parasitology 134, 763-776.

Poulin, R. (2010). Parasite manipulation of host behavior: an update and frequently asked questions. Advances in the Study of Behavior 41, 151-186. Purivirojkul, W. (2012). Histological change of aquatic animals by parasitic infection. In Histopathology - Reviews and Recent Advances (ed. Enrique Poblet Martinez), pp. 153-176. InTech.

R Core Team (2015). R: A Language and Environment for Statistical Computing.

Raymond, E. H. and Widder, E. A. (2007). Behavioral responses of two deep-sea fish species to red, far-red, and white light. Marine Ecology Progress Series 350, 291-298.

Rohrscheib, C. E. and Brownlie, J. C. (2013). Microorganisms that manipulate complex animal behaviours by affecting the host's nervous system. Springer Science Reviews 1, 133-140.

Schmid-Hempel, P. (2011). Evolutionary Parasitologythe Integrated Study of Infections, Immunology, Ecology, and Genetics. Oxford University Press, New York.

Seppälä, O., Karvonen, A. and Valtonen, E. T. (2004). Parasite-induced change in host behaviour and susceptibility to predation in an eye fluke-fish interaction. Animal Behaviour 68, 257-263.

Seppälä, O., Karvonen, A. and Valtonen, E. T. (2006). Host manipulation by parasites and risk of non-host predation: is manipulation costly in an eye fluke-fish interaction? Evolutionary Ecology Research 8, 871-879. Seppälä, O., Karvonen, A. and Valtonen, E. T. (2011). Eye flukeinduced cataracts in natural fish populations: is there potential for host manipulation? Parasitology 138, 209-214.

Seppänen, E., Kuukka, H., Huuskonen, H. and Piironen, J. (2008). Relationship between standard metabolic rate and parasite-induced cataract of juveniles in three Atlantic salmon stocks. Fournal of Fish Biology 72, 1659-1674.

Stumbo, A. D., Goater, C. P. and Hontela, A. (2012). Parasite-induced oxidative stress in liver tissue of fathead minnows exposed to trematode cercariae. Parasitology 139, 1666-1671.

Théron, A. (1984). Early and late shedding patterns of Schistosoma mansoni cercariae: ecological significance in transmission to human and murine hosts. The Fournal of Parasitology 70, 652-655.

Thomas, F., Adamo, S. and Moore, J. (2005). Parasitic manipulation: where are we and where should we go? Behavioural Processes 68, 185-199.

Ulenaers, P. and van Vessem, J. (1994). Impact of Great Crested Grebes (Podiceps cristatus L.) on fish ponds. Hydrobiologia 279/280, 353-366.

Vanderpham, J.P., Nakagawa, S. and Closs, G. P. (2012). Diel variation in use of cover and feeding activity of a benthic freshwater fish in response to olfactory cues of a diurnal predator. Environmental Biology of Fishes 93, 547-556.

Webster, J. P. (2007). The effect of Toxoplasma gondii on animal behavior: playing cat and mouse. Schizophrenia Bulletin 33, 752-756.

Wesołowska, W. and Wesołowski, T. (2014). Do Leucochloridium sporocysts manipulate the behaviour of their snail hosts? Fournal of Zoology 292, 151-155.

Widder, E. A., Robison, B. H., Reisenbichler, K. R. and Haddock, S. H.D. (2005). Using red light for in situ observations of deep-sea fishes. Deep Sea Research Part I: Oceanographic Research Papers 52, 2077-2085. 